\title{
Financial Industry Support Develops the Analysis of Influence on Small and Medium Enterprises: In Northwest Gansu, China
}

\author{
Xing Li* \\ LongDong University, Qing Yang City, Gansu, \\ 745000, China \\ e-mail: leebj@189.cn
}

\begin{abstract}
According to the time-series data from 2001 to 2011 and based on test of the residual and stability of VAR and by using the impulse response function and forecast valiance, this article established vector auto regressive model to analyze the dynamic relation between the development of Gansu small and medium enterprises and its financial support. The results indicate that the development of small and medium enterprises shows a positive response to the innovation of the size of financial industries institutions and tends to stabilize in certain conditions, which would have a negative response and then positive response to the innovation of banking businesses, and a positive response to the innovation of the financial efficiency.
\end{abstract}

Keywords-Financial Industries; Small and Medium Enterprises; VAR vector regressive model

\section{INTRODUCTION}

Located in the upper reaches of the Yellow River in northwestern China, Gansu province, with its vast landmass, multi-ethnic grounds 1200-year-long history, owns 14 subordinate prefectures and cities, in which most urban-rural economies are mainly small and medium enterprises except for a couple of large state-owned enterprises. In 2011, the state-owned industrial enterprises accounted for $8.73 \%$ of the total industrial output value, collective industries accounted for $0.77 \%$ and others (mainly SMES) accounted for $90.53 \%$ in national economic structure of Gansu, among which small businesses were mainly small-market-coverage and laborintensive processing trade enterprises, without proprietary intellectual rights and brands. The main restrictions to the development of Gansu SMES were size, credit, management risk, fiscal system and the basic conditions which could be used for mortgage. The policy support of government is quite essential for SMES, because the improvement in operating capability of them is helpful for their management(Turok I, Raco M, 2000), moreover, information asymmetry of SMES may lead to partially beneficial losses in their trade negotiations, which also cause the adverse selection and moral risk(La Porta, R; Lopez-de-Silanes, F; Shleifer, A). Still, SMES have to assume a certain risk in financing(Hellmann, T; Puri, M, 2000). By using the method of internal audit, they can control their own internal risk(xing.L,2013) and if diversified system of financial service and a new way of financing established to provide SMES with financial support, the fund demands of them could be met. However,

\author{
Ying Jia \\ RuiXin County Bank, Qing Yang City,Gansu \\ 745000, China \\ e-mail:wasiba_lee@wo.com.cn
}

SMES are badly effected by the level of development of financial industry, especially in western regions where economy is relatively backward. We use the VAR Model to analyses the dynamic relationships between financial level and the development of SMES in Gansu, and then put forward a few suggestions about some conclusions and problems.

\section{SELECTION \& ANALYSIS METHODS OF THE DATA:}

Based the samples from 2001 to 2011,the rate of added value of SMES to the GDP of Gansu was chosen as an indicator to measure the developmental level of SMES in Gansu, which was the important financial factor for effecting the development of SMES in Gansu. Asli Demirguc-kunt and Ross Levine mentioned in the world bank report,"the developmental level of a country or a region should be measured by the size, activity and efficiency of financial industry". The size, activity and efficiency of financial industry is represented respectively by the rate of the total assets of the banking industry, private credit of banking and the total output value of industry adds the operating profit in industry structure to the GDP of a country or a region; considering its relatively less interference in the scale of financial bond market and capital market, it can be neglected temporarily, and the developmental level of SMES, and the size, activity, efficiency of financial industry is represented respectively by DL,BS,BA,BF. To eliminate the influence of heteroscedasti city, all variables were taken their logarithms and all the data we used in the article came from the Statistical Yearbook of Gansu and the historical data of Gansu economic data network. We tested the stability of the variable itself firstly, and then established the VAR model which could forecast time series variables systematically. In the testing of stability and residual error of the VAR model, the pulse impact and variance analysis method was used to analyze the contributions of the established model in affecting the disturbance values of some variables in its relative path, with changing over time. The statistical software used in this article is Eviews6.0.

\section{ANALYSIS}

\section{A. Johansen Cointegration Test \&Granger Causality Test}

To avoid the return of the error, many dependent variable data were produced by the process of 
nonstationarity,so it was necessary to conduct an ADF test on the stationary of the variable data involved before establishing the regression equation to analyze them. The ADF test was used in the article to perform the root test of LNDL 、 LNBS 、 LNBA 、 LNBF and the results suggested that LNDL、LNBS、LNBA、LNBF met the first-order single whole when observed at the level of $5 \%$, as shown in table 1 , which in accordance with the premise of Johansen cointegration test. Both the cointegration results of the characteristic root test and the maximum test show

Table I

\begin{tabular}{|c|c|c|c|c|c|}
\hline \multirow[b]{2}{*}{ Variable } & \multirow[b]{2}{*}{$\mathrm{ADF}$} & \multicolumn{3}{|c|}{ AFD Examination of critical value } & \multirow[b]{2}{*}{ Prob* $^{*}$} \\
\hline & & 1\%Significance Level & $\begin{array}{c}\text { 5\% Significance } \\
\text { Level }\end{array}$ & $\begin{array}{c}\text { 10\% Significance } \\
\text { Level }\end{array}$ & \\
\hline$\triangle \mathrm{LNDL}$ & -6.0606 & -4.33933 & -3.587527 & -3.22923 & 0.0002 \\
\hline$\triangle \mathrm{LNBS}$ & -4.2139 & -4.356066 & -3.595026 & -3.233456 & 0.0140 \\
\hline$\triangle \mathrm{LNBA}$ & -4.9568 & -4.33933 & -3.587527 & -3.22923 & 0.0024 \\
\hline$\triangle \mathrm{LNBF}$ & $\begin{array}{c}- \\
33.7299\end{array}$ & -4.33933 & -3.587527 & -3.22923 & 0.0374 \\
\hline
\end{tabular}

that there is long-term cointegration relationship between $\triangle \mathrm{LNDL}$ and $\triangle \mathrm{LNBS} 、 \triangle \mathrm{LNBA} 、 \triangle \mathrm{LNBF}$, which aslo shows that there is a casual relationship between $\triangle \mathrm{LNDL}$ and $\triangle \mathrm{LNBS} 、 \triangle \mathrm{LNBA} 、 \triangle \mathrm{LNBF}$ at least in one direction. Tested by Grander causes and consequences analysis, it shows that there is a Grander causal relationship between $\triangle \mathrm{LNDL}$ and $\triangle \mathrm{LNBS}$ at obvious level of $10 \%$, which also explains that the development of the financial sector in Gansu can promote the development and reproduction of its SMEs, and the endogenous industry can promote the prosperity and development of financial industries. Besides, strengthening in the activity of the financial industries can also stimulate the development of the SMEs.

\section{B. The Establishment and Test of Vector Auto regression Model}

To establish the VAR model on the time series $\triangle \mathrm{LNDL}$ and $\triangle \mathrm{LNBS} 、 \triangle \mathrm{LNBA} 、 \triangle \mathrm{LNBF}$, and then using the criterion of the Akaike and Schwartz information to choose lag intervals for endogenous and confirming 1 as the lagged differences to establish combing with the siginificant test of T statistics equations.

1) Residual Test: In order to conduct further analysis of impulse response faction and equation decomposition on the equation, we firstly performed the test of residual error and stability of it. To analyze whether the residual error of Jarque Bers statistic equation accord with the hypothesis of normal distribution is to test whether the residual has heteroscedasticity by using the White test and whether the residual series has self-correlation by using LM statistics. The model shows that the residual series has no selfcorrelation and heteroscedasticity at the obvious level of $10 \%$.
2) Test of the Stability: According to Lutkpohl's description about the reciprocal of polynomial, provided that the reciprocals of all the root models of the estimated equation are less than 1,i.e.they are located in the unit circle, which proves that the VAR model is stable, otherwise, it is unstable and all the results are invalid, and then the AR root of the first order VAR model can be established as shown in the Fig1,which explains that the established model is stable with the prerequisite of impulse response analysis. Therefore, the VRA model passed the residual test and stability test,which could be used as the basis of conducting the impulse response

analysis and variance decomposition on the level sequence of the development of the SMEs and the finance in Gansu province.

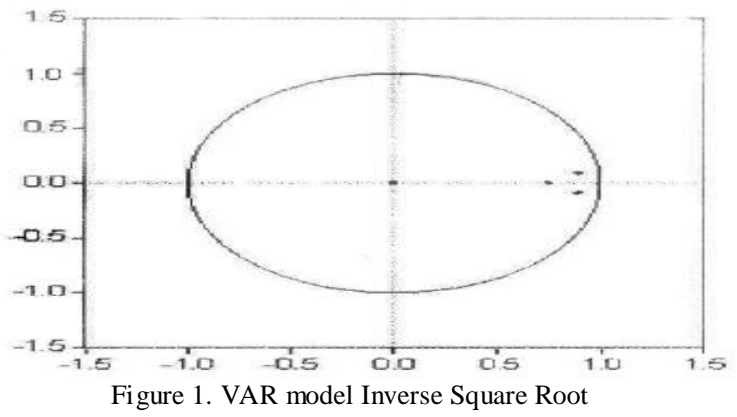

\section{The Analysis of Impulse Response:}

We found in the process of the analysis that the endogenous variable had a corresponding impulse response function as to each error term.Fig2 is the simulation of the impulse response function curves, in which the solid line stands for value of the response function and the vertical axis represents response degree of the dependent variable to explanatory variable and the horizontal axis shows test of the proposed response periods; it also shows that the development of the SMEs has a positive response on the standard deviation impact of the banking sector in the beginning, and reaches its highest value at the 8th trrm,and then the positive response falls down to smoothly, which explains that the enlarging in size of the banking sector has rapid and lasting influence 
on the SMEs in Gansu. The convergent tendency in the 8th period proves that the increasing of the SMEs slows down in the coming periods because the limit of its inherent features. From Fig2, it is also can be found that the development of the SMEs has a standard deviation impact on the activity of the banking sector, which is a negative response at the beginning, reaching its highest at the 3 rd term, and turning to positive response after the 6th term and then gradually increasing to the trend of convergence, which shows what the increasing activity of the banking sector in its early stages invests in the development of the SMEs in Gansu is not enough, with more resources invested into those large and mediumsized state-owned enterprises for large returns. It is not conducive to the development of the SMEs of Gansu at that stage, meanwhile,with the accumulation of the capital and basic skills of the SMEs and the optimizing of the cultural and organizational structure of the enterprise, banking sector has an increasing investment in the development of the SMEs of Gansu. Fig 2 shows that the development of the SMEs has an increasing positive response to the profitability of the banking sector and reaches its highest at the 7 th term, then turns to convergence. Thus the improvement of financial service efficiency in the banking sector in Gansu will increase the management and control of financing efficiency of the SMEs which will ensure and improve the development of the SMEs in Gansu.

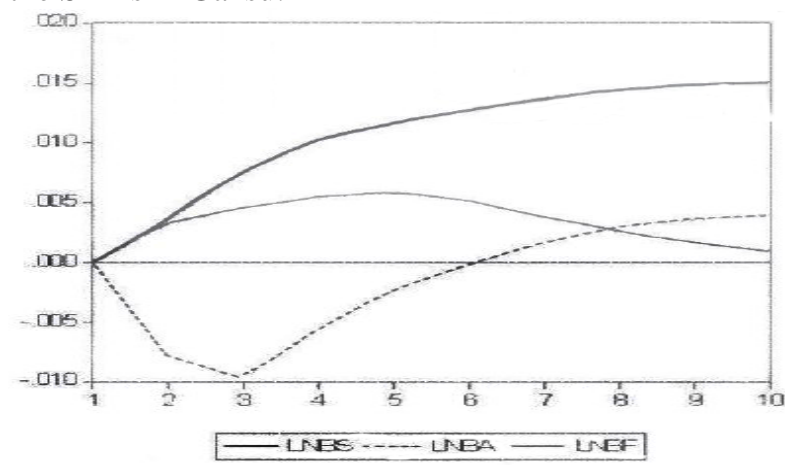

Figure 2. The pulse responds to Path curve

\section{Variance Decomposition Analysis:}

In analyzing $\operatorname{VAR}(1)$ model, the impulse response function was used to track the impact effect of the system to variable and the variance decomposition of the model showed the important information-----the forecasting criterion of the system was mistakenly analyzed as the impact of variables, which had a variance analysis on each internal variable.Table2 shows the VAR model 1 with term of 10 , and from which we can see the contributions of each structural impact to the internal variable through the variance decomposition reflected in the VAR model 1,as figure 3 shows.
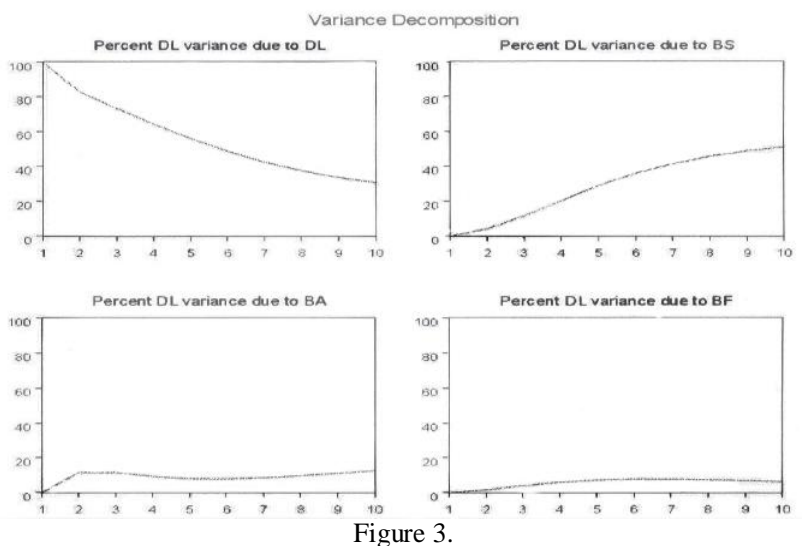

From table2,it is can be fond that the influence of the development of the SMEs by themselves is gradully reducing over time while the development of the banking size has a contrary influence on them ; while the influence of financial efficiency to the SMEs is gradually becoming strong and then weak, financial activity has a contrary influence on them, which fits with the results of the impulse response analysis in the figure 2 . It is can be seen in the figure 3 that the in flounce of the development of the SMEs by themselves is gradually declining to $30 \%$ and it is increasing close to $50 \%$ by the development of banking sector, which shows that the scale of the development of banking sector accounts for a large proportion in influencing the development of the SMEs. The profitability of financial activity mainly remains at $10 \%$, which explains that the influence of the key focus areas in the financial activity of Gansu or in the MLEs to the improvement of the SMEs doesn't meet its activity, but recently it has been improved a lot. In comparison, The profitability of financial efficiency stays below $10 \%$, which just has a little influence on the development of the SMEs. Thus it is consist ant with The profitability of financial activity, besides, it can be proved that intensification of the financial sector in Gansu is remained to be improved from the large proportion by the influence of the scale of financial sector.

\section{CONCLUSIONS \&SUGGESTIONS}

\section{A. Conclusions:}

according to the analysis mentioned above, it is canbe founded that the the development of the SMEs in Gansu has positive influences on one standard deviation impact of the financial scale, which trend to stable latter, because the bank loan is always the key foctor of the development of the SMEs for their lack of capital. The development of the SMEs has a negative influence firstly and then a positive one on the financial activity, which explains the process of bank to the loan of SMEs that is not accepted at first and then accepted. In short, the development of the SMEs has a positive response on the impulse of the financial efficiency, and the improvement in the financial efficiency will enable the promotion to the development of the SMEs in Gansu province. 


\section{B. Suggestions:}

to further expand the financial scale in Gansu and establish a more complete financial system so as to attract more commercial banks to Gansu, and as the large and medium-sized state-owned banks increase their stand credit line on the SMEs in Gansu, the pilot range of the new financial situations like microfinance companies, rural banks and so on should be actively expanded and the financing and distribution of the internal corporate bonds should be quicken. If permitted,SMEs in some ares should strive for as much risk investments as possible or become listed companies in the capital market. To increase the support activity of financial industry to SMEs, the government should strengthen its policy to support the SMEs and to positively solve the problems in loan guarantees of the SMEs,for example, the government may increase the quantities of the financing institutions and expand their scale under the rational micro-control, management and restriction. To improve the financial efficiency in Gansu and strength the innovation of the financial products of banks, the government should encourage those financial industries whose economic policies are closed and backward to innovate and to take the advantages over the ready financial derivatives and products, and expand range of the mortgage goods, such as the loan of note mortgage, loan of orders mortgage, loan of contract mortgage and so on, and then transform the working style of banking and improve the banking service. It is known to all that the innovation of the products and service in banking industries will bring the win-win of the SMEs and banking industries.

TABLE II VARIANCE DECOMPOSITION

\begin{tabular}{|c|c|c|c|c|c|}
\hline period & S. E. & DL & BS & BA & BF \\
\hline 1 & 0.016674 & 100 & 0 & 0 & 0 \\
\hline 2 & 0.019557 & 82.69281 & 4.046591 & 11.64541 & 1.614929 \\
\hline 3 & 0.021955 & 73.0144 & 11.58549 & 11.46646 & 3.933519 \\
\hline 4 & 0.024382 & 64.20254 & 20.53685 & 9.344181 & 5.926388 \\
\hline 5 & 0.026941 & 55.89311 & 28.96681 & 8.010944 & 7.135315 \\
\hline 6 & 0.029556 & 48.56735 & 35.97694 & 7.850022 & 7.605655 \\
\hline 7 & 0.032125 & 42.45054 & 41.43939 & 8.540753 & 7.569232 \\
\hline 8 & 0.034563 & 37.49965 & 45.55242 & 9.698201 & 7.249726 \\
\hline 9 & 0.036806 & 33.55318 & 48.59785 & 11.04312 & 6.805905 \\
\hline 10 & 0.038831 & 30.42772 & 50.83123 & 12.40566 & 6.335385 \\
\hline
\end{tabular}

\section{REFERENCES}

[1] Granger, C. W. J. Investigating causal relations by econometric models and cross spectral methods. Econometrical. 1969, (37): 424-438.

[2] Turok I, Raco M, 2000, "Developing expertise in small and medium-sized enterprises: an evaluation of consultancy support" Environment and Planning C: Government and Policy 18(4) 409 427

[3] Su,Norman Makoto,Wilensky,Hiroko N.;Redmiles, David F,Source: Computer Supported Cooperative Work: CSCW: An International Journal, v 21, n 2-3, p 111-162, June 2012

[4] Fujita, Masataka, 1995a, 'Small and Medium-Sized Transnational Corporations: Trends and Patterns of Foreign Direct Investment', Small Business Economics 7(3), 183-204

[5] Sensuse, Dana Indra; Lukman Knowledge Management Model and Strategy of Genetic Resources and Traditional Knowledge in Indonesia: International Journal of Computer Science Issues, v 9, $\mathrm{n}$ 2 2-2, p 480-488, 2012

[6] Head, Keith, John Reis and Deborah Swenson, 1995, 'Agglomeration Benefit and Location Choice: Evidence from Japanese Manufacturing Investments in the United States', Journal of International Economics 38, 199-222.

[7] Lixing, 'How to improve the Quality and Efficiency of Economic Audit on University leaders leaving',Journal of Longdong University,1,(2013),pp.99-101

[8] Knack, Stephen and Philip Keefer, 1995, 'Institutions and Economic Performance: Cross-Country Tests Using Alternative Institutional Measures', Economics and Politics 7(3), 207-227.
[9] Lixing, 'How to improve the Quality and Efficiency of Economic Audit on University leaders leaving',Journal of Longdong University,1,(2013),pp.99_101

[10] La Porta, R; Lopez-de-Silanes, F; Shleifer(2002), A, JOURNAL OF FINANCE, 57.1, pp.265-301

[11] Hellmann, T; Puri, M, 2000, The interaction between product market and financing strategy: The role of venture capital, REVIEW OF FINANCIAL STUDIES,13.4, pp.959-984

[12] Demirguc.Kunt,Asli,ErikFeyen, \&Ross.Levine."Optimal Financial Structures and Development: The Evolving Importance of Banks and Markets", Mimeo, World Bank, 2011.

[13] Gerschenkron,Alexander. "Economic Backwardness in Historical Perspective: A Book of Essays", Cambridge, MA: Harvard University Press, 1962.

[14] Hsieh, D.(1993).Implication of Nonlinear Dynamics for Financial Risk Management.Journal of Financial and Quantitative Analysis,28(1),41-46.

[15] D.H.Ahn,J.Boudoukh,M.Richardson,R.F.Whitelaw,Optimal risk management using options,Journal of Finance, 54 (1999), pp. 359375

[16] W.W. Hogan, J.M. Warren, Computation of the efficient boundary in the E-S portfolio selection model,Journal of Financial and Quantitative Analysis, 7 (1972), pp. 1881-1896

[17] Giannini, C, Topics in structural VAR econometrics. Lecture Notes in Economics and Mathematical Systems No. 381, Springer-Verlag, Berlin, 1992.

[18] Hatemi-J, A. Asymmetric causality tests with an application. Empirical Economics. 2012, 42 (6): forthcoming. doi:10.1007/s00181-011-0484-x 